\title{
Öğretmen Adaylarının Çokkültürlü Eğitime Yönelik Tutumlarının Yordayıcıları Olarak Suriyelilere Yönelik Toplumsal Uzaklık ve Bilişsel Esneklik*
}

\author{
Social Distance And Cognitive Flexibility For Syrians As A \\ Predictor of The Teacher Candidates 'Attitudes of \\ Multicultural Education
}

\begin{abstract}
Binaz BOZKUR**, Binnaz KIRAN*** Devrim ALICI****
Öz: Bu çalışmada öğretmen adaylarının çokkültürlü eğitime yönelik tutumlarının Suriyeli sığınmacılara yönelik toplumsal uzaklık ve bilişsel esneklik değişkenleri tarafından yordanıp yordanmadığını incelemek amaçlanmaktadır. Araştırma betimsel bir çalışmadır. Araştırmaya $285(\% 54,2)$ kadın, 241 (\%45,8) erkek olmak üzere 526 öğretmen adayı katılmıştır. Araştırmada Bilişsel Esneklik Ölçeği, Öğretmenlerin Çokkültürlü Tutum Ölçeği, Bogardus Toplumsal Uzaklık Ölçeği ve Kişisel Bilgi Formu'ndan yararlanılmıştır. Yapılan analizler sonucunda öğretmen adaylarının çokkültürlü eğitime yönelik tutumları ile toplumsal uzaklığın düşük olması ve bilişsel esneklik arasında pozitif ve anlamlı bir ilişki olduğu gözlenmiştir. Uygulanan aşamalı çoklu doğrusal regresyon analizinde toplumsal uzaklık ve bilişsel esneklik değişkenlerinin öğretmen adaylarının çokkültürlü eğitime yönelik tutumlarının anlamlı yordayıcıları olduğu bulgusuna ulaşılmıştır. İki değişken varyansın toplam \% 20'sini açıklamaktadır. Sonuç olarak öğretmen adaylarının çokkültürlü eğitime yönelik tutumlarında hem kişisel özelliklerinin hem de toplumsal olarak diğer gruplara bakışlarının etkili olduğu görülmektedir. Türkiye'nin hem kendi kültürel çeşitliliği hem de göç vb. olgularla daha da yaygınlaşan çokkültürlü yapısı öğretmenlerin çokkültürlülüğe yönelik farkındalıklarının geliştirilmesini daha elzem kılmaktadır.
\end{abstract}

Anahtar Kelimeler: Suriyeli mülteciler, toplumsal uzaklık, bilişsel esneklik, çok kültürlü eğitim, öğretmenlik

\begin{abstract}
This study aims to examine whether teacher candidates' attitudes towards multicultural education are predicted by the variables of social distance towards Syrian refugees and cognitive flexibility. The research is a descriptive study. 526 teacher candidates, 285 (54.2\%) women and 241 $(45.8 \%)$ men, participated in the study. Cognitive Flexibility Scale, Teachers' Multicultural Attitude Scale, Bogardus Social Distance Scale and Personal Information Forms were used in the research. The results showed that there was a positive significant relationship between positive attitudes towards multicultural education and low social distance $(\mathrm{r}=356)$. Also, a positive significant relationship between positive attitudes towards multicultural education and cognitive flexibility. The result of regression analysis showed that variables of social distance and cognitive flexibility had a significant role on predicting pre-service teachers' attitudes towards multicultural education. The two variables explain a total of $20 \%$ of the variance. As a result, it is seen that both the personal characteristics and the social perspective of the teacher candidates in the attitudes towards multicultural education are effective. Turkey's cultural diversity and its multicultural structure with both more widespread migration etc. also makes teachers more essential for the development of multicultural awareness.
\end{abstract}

Keywords: Syrian refugees, social distance, cognitive flexibility, multicultural education, teaching

\footnotetext{
*Bu çalışmanın bir kısmı 4-7 Nisan 2018 tarihinde Antalya'da yapılan II. Uluslararası Avrasya Sosyal Bilimler Kongresi'nde sözel bildiri olarak sunulmuştur.

**Arş. Gör. Dr. Mersin Üniversitesi Eğitim Fakültesi, Mersin-Türkiye, Orcid ID: 0000-0002-3821-7489, e-mail: b.bozkur@hotmail.com

***Prof. Dr. Mersin Üniversitesi Eğitim Fakültesi, Mersin-Türkiye, Orcid ID: 0000-0002-8085-7914, e-mail: binkiran2009@gmail.com

****Prof. Dr. Mersin Üniversitesi Eğitim Fakültesi, Mersin-Türkiye, Orcid ID: 0000-0001-5542-0609, e-mail: devrimoalici@gmail.com
} 


\section{Giriş}

Günümüzde "nasıl bir öğretmen?" sorusu sürekli tartışılmaktadır. Çünkü öğretmenler, eğitimin niteliği ve kalitesini büyük ölçüde etkilemektedir. Bazen alan uzmanlığı ve öğretmenlik bilgisi yetersiz kalmaktadır. $\mathrm{Bu}$ nedenle öğretmenlerin özel uzmanlık alan bilgisi ve becerisi, öğretmenlik meslek bilgisinin yanı sıra öğrenciyle ilişkisini direk etkileyecek bazı özelliklere de sahip olması gerekmektedir. Özellikle dünya ve toplum sorunlarına duyarlı, demokrasiyi tüm kurum ve değerleriyle benimseyen, farklı inanç, görüş ve grupları uzlaştırabilen ve çokkültürlü ortamlarda hizmet verebilen kişiler olmaları beklenmektedir (Şişman, 2006). Çok kültürlülük ırk, etnik yapı, dil, cinsel yönelim, cinsiyet, yaş, engelli olma, sosyal sınıf, dini yönelim ve diğer kültürel faktörleri içeren çok yönlü bir kavramdır (APA, 2002). Nieto ve Bode (2008) ise çok kültürlülüğ̈̈; çoğulculuğu vurgulama, rrkçılıkla ve önyargılarla yüzleşme ve çeşitli bakış açılarından gerçekleri görme durumu veya hali olarak tanımlamışlardır. Çokkültürrlülük tanımlarında farklılık kavramı oldukça geniş bir biçimde ele alınmakta ve bu farklılık; dil, dini inanç, mezhep, etnisite, cinsiyet, yaş, engel durumu, cinsel yönelim ile birlikte insanların bireysel ve toplumsal olarak belirledikleri her türlü inanç ve uygulamaları kapsamaktadır (Polat ve Kılıç, 2013). Çok kültürlülük toplumun doğal olarak çokkültürlü olduğu veya savaşlar, ekonomik durum, vb. nedenlerle insanların ait oldukları topraklardan göç etmesi sonucunda çokkültürlü toplumlar için gittikçe önem kazanan bir kavramdır. Bu kavramın çeşitli boyutlarıyla sosyoloji, siyaset bilimi, felsefe ve eğitim bilimi gibi birçok farklı disiplinin konusu olduğu bilinmektedir (Yazıcı, Başol ve Toprak, 2009).

Çokkültürlülüğün en çok tartış1ldığ alanlardan biri de eğitimdir ve alan yazında çokkültürlü eğitim, kültürlerarası eğitim vb. kavramların sıklıkla yer aldığı görülmektedir. Banks (2008) çokkültürlü eğitimi, tüm öğrencilere etnik, kültürel ve dilsel alternatifler sağlayarak, tüm öğrencilerin eşit eğitim hakkından yararlanmalarını sağlayan bir eğitim yaklaşımı olarak tanımlamaktadır. Özellikle tarımdan sanayiye ve sonrasında bilgi toplumuna geçişin, meydana gelen göçlerin ve ülkeler arasında, sosyal, ekonomik, vb. amaçlarla oluşturulan birliklerin çokkültürlü eğitimin önemini artırdığını söylemek mümkündür. Toplumların yerellikten küreselliğe doğru bir geçiş yaşadığı bu dönem, eğitimde evrensel ilkelerin oluşturulmasını, farklı kültürlerin tanınmasını ve kültürler arasındaki etkileşimin hızlanmasını zorunlu kılmaktadır. Ayrıca çağdaş toplumlarda, yetiştirilen kişilerin diğer kültürlerle etkileşim içerisinde olmaları ve bu temaslarında olumlu tutumlar geliştirmeleri beklenmektedir (Cırık, 2008). Dolayısıyla çokkültürlü eğitim çağımızın önemli gerekliliklerinden biridir.

Gay (1994), eğitim alanındaki herkesin çokkültürlü eğitim uygulamalarında aktif olarak rol alması gerektiği belirtmektedir. Eğitiminde en önemli faktörlerden birisi öğretmenlerdir. Bu nedenle öğretmenlerin çokkültürlülüğe yönelik tutumları ve yeterlikleri çokkültürlü eğitimi doğrudan etkilemektedir. Gay (2002) öğretmenlerin sahip olması gereken çokkülttürlü yeterlikleri; kendi kültürel kimliği ve ön yargılarına ilişkin farkındalık, kendi kültüründen farklı olan grupların dünya görüşlerini öğrenmeye isteklilik ve kültüre duyarlı öğretim yöntemlerini geliştirme boyutlarını içeren yetenekler olarak belirtmiştir.

$\mathrm{Bu}$ araştırmada öğretmenlerin çokkültürlü eğitime yönelik tutumlarının belirleyicisi olduğu düşünülen değişkenlerden birisi toplumsal uzaklıktır. Toplumsal uzaklık kavramı, mesafe koyma sürecini çeşitli toplumsal yapılarda üretilen faktörler ile tanımlayan ünlü sosyolog Simmel ile başlayan sosyolojik geleneğin bir parçasıdır (Bichi, 2008). Toplumsal uzaklık olgusu ilk olarak Amerika'daki irklar arasındaki ilişkileri inceleyen Bogardus (1933; Akt. Coenders, Lubbers ve Scheepers, 2005) tarafından gözlemlenmiş ve azınlık grupların çoğunluk olan gruplara yaklaştıkça çoğunluk grupların azınlık grupları belli bir mesafede tutmaya ve etnisiteler arasındaki gerçek teması önlemeye çalıştığını öne sürmüştür. Bogardus, bu iddiayı destekleyen güçlü kanıtlar bulmuş, bu kanıtlarla kalıcı bir araştırma geleneği oluşturmuş ve sosyal mesafe konusunda hala benzer sonuçlar veren çağdaş araştırmalara öncülük etmiştir (Coenders, Lubbers ve Scheepers, 2005). Genel olarak toplumsal mesafe kişinin kendisini ait gördügü sosyal kategorinin dışında algıladığı ve kendi sosyal kategorisinin dışında kabul ettiği kişilere yönelik olarak çeşitli yoğunlukta ilişkiye açık olmama durumu ve 
varlıklarını kabul etmedeki eksiklik olarak tanımlanmaktadır (Bichi, 2008). Bogardus (1925; Akt. Karsl1, 2012) ise toplumsal mesafeyi, belirli bir sosyal sınıfa üye olan herhangi bir kişinin, diğer sınıflarla ve o sınıflardan gruplar ve insanlarla olan hiyerarşik ilişkilerini, bir nüfus içindeki sınıfların birbirleri ile olan ilişkilerini ve belirli nüfusların aralarındaki toplumsal farklılık ilişkilerine işaret eden bir kavram olarak tanımlamaktadır. Toplumsal mesafenin temel belirleyicilerinin daha çok 1rk, milliyet, din ve meslek gibi kategoriler olduğu belirtilmekte ve bu kategorilere verilen önem kültürden kültüre farklılık gösterebilmektedir (Charnes ve Gnezy, 2008). Bogardus'a (1925) göre toplumsal mesafe, sosyal grupların birbirlerini algılamadaki yakınlık dereceleri (komşuluk etmek, arkadaşlık etmek, evlenmek gibi) olarak sosyal değerlendirme ve onaylamaya işaret etmektedir.

Ülkelerindeki şiddet, savaş ve zulüm nedeniyle göçe zorlanan bireylerin sayısı küresel çapta rekor düzeye varmıştır. Türkiye, 2016 yılı sonunda art arda üç yıl, dünyada en kalabalık mülteci nüfusa ev sahipliği yapan ülke olmayı devam ettirmiştir. Türkiye, 3,5 milyonu aşan kayıtlı Suriyeli mülteci ile beraber Birleşmiş Milletler Mülteciler Yüksek Komiserliği’ne (UNHCR) kayıtlı 365.000'den fazla diğer uyruklardan kişiye de ev sahipliği yapmaktadır (UNHCR, 2018).

Göçle gelen Suriyeli ailelerin çocukları (mülteci/sı̆gnmacı) eğitimlerine Türkiye'de devam etmektedir. UNHCR (2017) eğitim raporuna göre Suriyeli mülteci çocukların \% 40'1 okul dışıdır; kayıtlı Suriyeli çocukların sayısı 2016'da 500.000'e ulaştı: üniversiteye 18-25 yaş arası gençlerin \% 3'ünden azı devam edebilmektedir. Önceleri kamplarda ve geçici eğitim merkezlerine devam ederken bu çocuklar 2017-2018 Eğitim Öğretim y1lından itibaren artık Türk okullarına devam etmektedirler. Bu nedenle onların eğitimini sağlayacak öğretmenlerin toplumsal uzaklıklarının ve çokkültürlü eğitime yönelik tutumlarının incelenmesi önemli olmaktadir.

Farklı bir ülkeden gelen gruplara yönelik olumsuz tutumlar dünya genelinde yaygın ve tipik olarak düşmancadır, çünkü çoğu göç alan ülke vatandaşı göç edenleri güvenlik tehdidi ve ekonomik bir yük olarak algılamaktadır (Koç ve Anderson, 2018). Türkiye'ye göç eden Suriyelilere yönelik ise olumsuz tutumların az olduğuna (Çiftçi, 2018; Sağlam ve İlksenKambur, 2017) yönelik çalışmalara da rastlanmakla birlikte özellikle Türkiye'ye göç eden Suriyelilerin ülkelerine geri dönmeyecekleri ve kalıcı olacaklarının anlaşılması ve Türkiye'de yaşayan Suriyeli sayının artması olumlu algının olumsuza doğru evrilmesini beraberinde getirmiştir (Cengiz, 2015; Erdoğan, 2014; Yıldırımalp, İslamoğlu ve İyem, 2017). Yapılan çalışmalar Türk toplumunun Suriye'den göç eden kişiler ile arasında çok ciddi bir kültürel mesafe koyduğunu, onlara vatandaşlık verilmesine hiç olumlu bakmadığını göstermektedir (Aktaş ve Gülçur, 2017; Erdoğan, 2014). Suriyelilere yönelik kültürel mesafe ve olumsuz tutumların ötekileştirme pratikleri olarak tezahür ettiğini gösteren araştırma bulguları (Çömez Polat ve Kaya, 2017) ve Suriyelilerin günah keçisi veya olağan şüpheliler olarak görülmeye başlanması (Man, 2016) bu konudaki riskleri göstermesi açısından dikkat çekicidir. Olumsuz tutuma sahip olan gruplar içerisinde üniversite öğrencileri (Kabaklı-Çimen ve Ersok Quadir, 2018) ve özellikle farklı inanç, görüş ve grupları uzlaştırabilen ve çalışan ve çokkültürlü ortamlarda hizmet verebilen kişiler olmaları beklenen öğretmenlerin (Şişman, 2006) de yer alması (Topkaya ve Akdağ, 2016) endişe vericidir.

Öğretmenlerin çokkültürlü eğitime yönelik tutumlarında içinde yaşadıkları toplum ve aldıkları eğitimin yanı sıra kişisel özelliklerinin de etkili olabileceği düşünülmektedir. Bu kişisel özelliklerden biri de bilişsel esnekliktir. Bilişsel esneklik; problem çözme durumunda veya bireyin durumsal olarak değişen ihtiyaçlara uyacak şekilde kendiliğinden bilgisini yeniden yapılandırarak, bilgisinin çeşitli ögelerini uygun bir şekilde yeniden birleştirme yeteneği olarak tanımlanmaktadır (Kearsley, 2000). Bilişsel esnekliği, Martin, Anderson ve Thweatt (1998) bireyin, alternatiflerin farkında olması, yeni durumlara uyum sağlama konusunda esnek olabilmesi, esnek olabildiği durumlarda kendisini yetkin hissetmesi olarak tanımlarken; Bilgin (2009) bilişsel esnekliği problemlere farklı çözüm yolları bulma; Gülüm ve Dağ (2012) ise değişen çevresel koşullara göre bilişleri değiştirebilme yetisi olarak tanımlamışlardır. Ayrıca Canas, Fajardo ve Salmeron (2013), bilişsel esnekliği yeni ortamlar ve beklenmedik koşullar 
karşısında, bilişsel işlem stratejilerine uyum sağlayan insan yeteneği diye belirtmişlerdir. Tanımlarda da görüldüğg̈ gibi bilişsel esneklik bireylerin yaşamlarında karşılaştıkları beklenmedik durumlarla baş edebilmeleri için bilişsel, duyuşsal ve davranışsal alanlarda değişiklik yapabilme, olaylarla baş edebilme becerilerine sahip olmaktır.

Bilişsel esneklik üç önemli insan özelliklerini içermektedir. Birincisi; deneyim ile elde edilebilen bir öğrenme sürecini anlatan yetenek, ikincisi; bilişsel esneklik bilişsel işlem stratejilerine uyumu gerektirir ki bu stratejiler bir problem alanında aranan işlemlerin dizisidir. Bu nedenle bilişsel esneklik; karmaşık durumlardaki farklı tepkileri değil, davranış değişikliğini ifade etmektedir. Son olarak; kişinin bir süredir bir görevi yerine getiriyor olması, yeni ve beklenmedik bir değişikliği oluşturacaktır (Canas, Fajardo ve Salmeron, 2013). Bireylerde esnek bir uyum potansiyeli olmasına rağmen bu uyum sağlama her zaman olmayabilir. Bunun nedeni de kişinin çevresel değişikliklerle başa çıkabilmesi için esnek olması gerektiği durumlardaki bilişsel katılığıdır (Canas, Fajardo ve Salmerón, 2013). Bilişsel esnekliğin sosyal ilişkiler yoluyla sınandığı söylenebilir. Sacharin'e (2009) göre bilişsel esneklik türlerinden İlişkisel esneklik, yeni fikirler üretebilmeyi sağlayan yaratıcılıkla ilgilidir ve olgular arasında olağandışı ilişkiler kurabilmeyi açıklamaktadır. Sosyal psikolojiyle ilgili çalışmalarda bilişsel esnekliğin genellikle ilişkisel esneklik ölçümleri aracılığıyla incelendiğini vurgulamaktadır.

Bilişsel Esnekliğe sahip olmayı Chung, Fengsu ve Wensu (2012) ve Martin, Anderson ve Thweat (1998) anlaşmazlıklara karşı yüksek tolerans gösterebilme, değişen yeni durumlara uyum sağlayabilme, iç görü sahibi olma; Bilgin (2009) ise etkili problem çözme ve kaygıyla baş edebilme becerisine sahip olma, kişilerarası ve sosyal ilişkilerde uyumlu ve başarılı ve sosyal yetkinliğin yüksek olması olarak belirtmişlerdir. Ek olarak Diril (2011) bilişsel esnekliğe sahip bireylerin öfkeyle baş edebilme becerisine sahip olduklarını belirtirken, Martin, Stagers ve Anderson (2011) ise bu bireyleri kendine güvenen, başkalarının ihtiyaçlarına karşı duyarlı, entelektüel esnekliği yüksek, kendine merhamet edebilen yani yaptığı hatalar karşısında kendini affedebilen bireyler olarak belirtmektedirler.

Alanyazın incelendiğinde öğretmenlerde bilişsel esnekliği inceleyen çeşitli araştırmaların yapıldığı gözlenmiştir. Örneğin Üzümcü ve Müezzin (2017) tarafından yapılan bir araştırmada öğretmenlerin bilişsel esneklik düzeyleri arttıkça mesleki doyum düzeylerinin de arttığı sonucuna ulaşılmıştır. Yaşar Ekici ve Balc1, 2019) ise öğretmenlerin bilişsel esneklik düzeyleri arttıkça duygusal tepkiselliklerinin de azaldığını saptamışlardır. Buna paralel olarak Gündüz (2013) tarafından yapılan bir araşırmanın sonuçları öğretmen adaylarında bilişsel esnekliğin anksiyete ve depresyon ile anlamlı negatif korelasyona sahip olduğunu ortaya koymuştur. Öğretmen adaylarında bilişsel esneklik ve özyeterlik algılarını inceledikleri bir araştırmada Gürbüz ve Nartgün (2018) bilişsel esneklik arttıkça öğretmenlerde özyeterlik algısının da arttı̆̆ını belirlemişlerdir. Bu araştırma sonuçları öğretmenlerde bilişsel esnekliğin önemini göstermesi açısından dikkat çekicidir.

Türkiye'de öğretmenler Kamu Personeli Seçme Sınavı (KPSS) sonucunda aldıkları puanlara göre Türkiye'nin farklı bölgelerindeki il ve ilçelerinde göreve başlamaktadırlar. Bu öğretmenlerden ait olduğu veya aşina olduğu yerlerin dışına atanan kişilerin farklı kültürlerle temas halinde olması büyük bir olasılıktır. Öğrencilerin farklı, etnik köken, sınıf, cinsiyet, dil, 1rk, inanç sistemi, deneyim, cinsel yönelim ve politik görüşe sahip olabileceklerini idrak etmek, bu farklıl1kları kabul etmek ve öğretim ortamının düzenlenmesinde dikkate almak, öğrencilerin farklılıklarını önyargısız bir biçimde tartışmaya açık olmak kültürel çeşitliliği sınıf ortamına taşıma konusunda önemli bir faktördür. Gelecek kuşakların yetişmesinde önemli katkısı olan ve giderek karmaşıklaşan koşullara uyum sağlama noktasında onlara en fazla desteği sağlaması gereken öğretmenlerin bu değişen olaylara uyum sağlayabilmeleri ve bu problemlerle etkin bir şekilde baş edebilmeleri beklenmektedir. Bu da bireylerin bilişsel olarak esnek olması, çokkültürlülüğe duyarlı ve bu konuda farkındalığının yüksek olmasıyla mümkündür.

$\mathrm{Bu}$ durum dikkate alınarak bu çalışmanın amacı öğretmen adaylarının çokkültürlü eğitime yönelik tutumlarının Suriyeli sığınmacılara yönelik toplumsal uzaklık ve bilişsel esneklik değişkenleri ile ilişkili olup olmadığı ve bu değişkenler tarafından yordanıp yordanmadığının incelenmesidir. Bilişsel esnekliği yüksek bireylerin farklı kültürden gelen 
bireyleri kabulünün daha hızlı ve yaklaşımının daha olumlu olması beklenmektedir. Bu nedenle bu çalışma, günümüzde yoğun olarak farklı kültürlerden gelen öğrencilerle çalışan öğretmenlerin çokkültürlü eğitime yaklaşımında rol oynayan etmenleri ortaya koyması açısından önem taşımaktadır. Ayrıca alanyazın incelemesinde, öğretmen adaylarının çokkültürlü eğitime yönelik tutumlarının toplumsal uzaklık ve bilişsel esneklik değişkenlerine göre incelendiği herhangi bir araştırmaya rastlanmamıştır. Bu anlamda da çalışmanın alanyazına önemli bir katkı sağlaması beklenmektedir.

\section{Yöntem}

$\mathrm{Bu}$ araştırma, öğretmen adaylarının çokkültürlü eğitime yönelik tutumlarının bilişsel esneklik ve toplumsal uzaklık düzeyleri tarafından yordanıp yordanmadığını ortaya koymayı amaçlayan ilişkisel bir araştırmadır. İlişkisel araştırmalar, doğası gereği neden sonuç ilişkisi kurulamayan, pratik nedenlerle değişimleme veya denetimin yapılamadığı veya kısmen yapıldığı çalışmalardır (Erkuş, 2011).

\section{Örneklem/çalışma grubu}

Araştırmaya, 2017-2018 eğitim/öğretim yılında Mersin Üniversitesi Eğitim Fakültesi'nde Pedagojik Formasyon eğitimine devam eden $285(\% 54,2)$ kadın, $241(\% 45,8)$ erkek olmak üzere 526 öğretmen adayı katılmıştır.

\section{Veri toplama araçları}

Araştırma verilerinin elde edilmesinde üç farklı ölçme aracı ve araştırmacılar tarafından hazırlanan Kişisel Bilgi Formu kullanılmıştır. Ölçme araçlarını geliştiren kişilerden ölçeklerin kullanımı için izin alınmıştır. Ölçme araçlarıyla ilgili tanıcı bilgiler aşağıda sunulmuştur.

Bilişsel Esneklik Ölçeği (BEÖ). Bu çalışmada Martin ve Rubin (1995; Akt. Çelikkaleli, 2014) tarafından geliştirilen ve Çelikkaleli (2014) tarafından Türkçe'ye uyarlanan Bilişsel Esneklik Ölçeği kullanılmıştır. Ölçek 11 madde ve tek boyuttan oluşmakta ve altılı Likert tipi bir ölçektir. Çelikkaleli'nin (2014) yaptığı uyarlama çalışmasında, ölçme aracının Cronbach Alfa iç tutarlık katsayıs1 .80, test-tekrar test güvenirlik katsayıs1 ise 0.83 olarak hesaplanmıştır. Ölçme aracından alınan puanların yüksekliği bilişsel esnekliğin yüksek olduğuna işaret etmektedir.

Öğretmenlerin Çokkültürlü Eğitim Tutum Ölçeği. Bu araştırmada Ponterotto, Baluch, Greid ve Rivere (1998) tarafından geliştirilen ve Yazıcı, Başol ve Toprak (2009) tarafından Türkçe'ye uyarlanan Öğretmenlerin Çokkültürlü Tutum Ölçeği (ÖÇTÖ) kullanılmıştır. Ölçek 5'li likert tipindedir. Ölçeğin orijinal formuna ait Cronbach Alfa katsayısı 0.86; Türkçe formunun Cronbach Alfa katsayısı ise 0.75 olarak hesaplanmıştır. Ölçeğin iki yarı güvenirliği ise 0.72 olarak hesaplanmıştır. Alınan puanların yüksekliği öğretmenlerin çokkültürlü eğitime ilişkin tutumlarının olumlu olduğunu göstermektedir.

Bogardus Toplumsal Uzaklık Ölçeği. Toplumsal Uzaklık ölçeği, insanların diğer ırklar, dinler ve sinıflardan olan kişilerle ilişkilerin kabul veya reddetme derecelerini belirlemek amaciyla Bogardus tarafından 1925 yılında geliştirilmiş̧ir (Tavşancıl, 2006). Bogardus Toplumsal Uzaklık Ölçeği'nde, "İlk duygusal tepkilerime göre aşağıda adı geçen etnik toplulukların üyelerinin çeşitli ilişki gruplarından bir ya da birkaçını kabul ederim" şeklinde bir yönergeyle birlikte yedi madde yer almaktadır. Bu maddeler, bir bireyin farklı gruplardaki insanlara yönelik tutumlarını belirlemek amacıyla, "evlenebilirim", "dost olabilirim", "komşum olabilir", aynı işte çalışabilirim", sadece iletişim kurarım", "komşum olmasını istemem" ve "aynı ülkede yaşamak istemem" ifadelerinden oluşmaktadır (Seçer, 2015). Ölçekteki maddeler "kesinlikle katılmıyorum (1)" ve "kesinlikle katılıyorum (5)" şeklindedir. Ölçme aracından alınan yüksek puan öğretmenlerin ilgilenen gruplara yönelik toplumsal uzaklık düzeylerinin düşük olduğunu; kendilerini ilgili gruplara yakın hissettiklerini göstermektedir. 


\section{Verilerin analizi}

Araştırmaya katılan 541 öğretmen adayından elde edilen veriler öncelikle uç değer analizine tabi tutulmuştur. Yapılan analiz sonucunda 15 gözlemin uç değer verdiği belirlenmiştir. İlgili gözlemler analiz dışı tutularak 526 öğretmen adayı üzerinden elde edilen veriler dikkate alınmıştır. Kayıp veri analizi sonucunda, kayıp verilerin dağılımının rasgele olduğu belirlenmiş ve kayıp veri yerine ortalama atama yapmak suretiyle düzenleme yapılmıştır. Tüm analizlerde $\alpha=0,05$ alınmıştır. Verilerin analizinde normal dağılım varsayımının karşılanıp karşılanmadığının belirlenmesi için basıklık ve çarpıklık katsayıları incelenmiştir. Köklü, Büyüköztürk ve Çoklu-Bökeoğlu (2007) çarpıklık katsayısının -1 ve +1 aralığında olmasının dağılımın normalden aşırı sapmadığını işaret ettiğini ifade etmişlerdir. Yapılan analizlerde çarpıklık katsayısını -1 ve +1 aralığında olduğu gözlendiğinden dağılımın normal olduğu kabul edilmiştir.

\section{Bulgular}

Öğretmen adaylarının çokkültürlü eğitime yönelik tutumları ile bilişsel esneklik ve Suriyelilere yönelik toplumsal uzaklıkları arasındaki ilişkinin incelenmesi için Pearson Momentler Çarpımı Korelasyon değerleri hesaplanmış ve analiz sonuçları Tablo 1'de sunulmuştur.

Tablo 1.

Öğretmen Adaylarının Çok Kültürlü Eğitime Yönelik Tutum, Suriyelilere Yönelik toplumsal Uzaklık ve Bilişsel esneklikleri Arasındaki Korelasyon Değerleri

\begin{tabular}{llll}
\hline Değişkenler & 1 & 2 & 3 \\
\hline 1.Çokkültürlü Eğitime Yönelik Tutum & - & & \\
2. Toplumsal Uzaklık & $.356^{* *}$ & - & \\
3. Bilişsel Esneklik & $.258^{* *}$ & .014 & \\
\hline
\end{tabular}

**.Korelasyonlar 0.01düzeyinde anlamlıdır.

*. Korelasyonlar 0.05 düzeyinde anlamlıdır.

Tablo 1 incelendiğinde katılımcıların çokkültürlü eğitime yönelik tutumları ile Suriyelilere yönelik toplumsal uzaklıkları arasında pozitif yönde ve orta düzeyde, Çokkültürlü eğitime yönelik tutumları ile bilişsel esneklik düzeyleri arasında ise pozitif yönde düşük düzeyde anlamlı bir ilişki olduğu görülmektedir. Katılımcıların toplumsal uzaklık ve bilişsel esneklikleri arasındaki ilişki ise anlamlı değildir.

Öğretmen adaylarının çokkültürlü eğitime yönelik tutumlarının Suriyelilere yönelik toplumsal uzaklıkları ve bilişsel esneklikleri tarafından yordanıp yordanmadığını belirlemek için aşamalı çoklu doğrusal regresyon analizi yapılmış ve sonuçlar Tablo 2‘de sunulmuştur.

Tablo 2.

Öğretmen Adaylarının Çok Kültürlü Eğitime Yönelik Tutumlarının Suriyelilere Yönelik Toplumsal Mesafe Ve Bilişsel Esneklikleri Tarafından Yordanmasına İlişkin Aşamalı Doğrusal Regresyon Analizi Tablosu

\begin{tabular}{lcllllllll}
\hline $\begin{array}{l}\text { Yordanan } \\
\text { Değişken }\end{array}$ & Model & $\begin{array}{l}\text { Yordayıc1 } \\
\text { Değişkenler }\end{array}$ & $\mathrm{B}$ & $\mathrm{Sh}$ & $\beta$ & $\mathrm{t}$ & $\mathrm{p}$ & $\mathrm{R}$ & $\mathrm{R} 2$ \\
\hline $\begin{array}{l}\text { Çokkültürl } \\
\text { ü Eğitime }\end{array}$ & 1 & $\begin{array}{l}\text { Sabit } \\
\text { Toplumsal }\end{array}$ & 95.86 & 2.10 & & 46.59 & & & \\
$\begin{array}{l}\text { Yönelik } \\
\text { tutum }\end{array}$ & 2 & $\begin{array}{l}\text { Mesafe } \\
\text { Bilişsel } \\
\text { Esneklik }\end{array}$ & .51 & .09 & .36 & 8.71 & .00 & .36 & .13 \\
\hline
\end{tabular}

Toplam: $\mathrm{R}_{2}=.20, \mathrm{~F}=75.84 \mathrm{P}<.05$ 
Yapılan regresyon analizinin sonuçları incelendiğinde regresyonun 2 aşamada tamamlandığı gözlenmektedir. Varyansa katkıları açısından sırayla Suriyelilere yönelik toplumsal uzaklık ve bilişsel esnekliğin öğretmen adaylarının çokkültürlü eğitime yönelik tutumlarının anlamlı yordayıcıları olduğu görülmektedir. Birinci aşamada sadece toplumsal uzaklık değişkeni modele dâhil edildiğinde bu değişkenin toplam varyansin \%13'ünü açıkladığı görülmektedir $\left(\mathrm{R}=.36, \mathrm{R}_{2}=.13, \mathrm{P}<.00\right)$. İkinci aşamada bilişsel esneklik değişkeni modele eklendiğinde açılanan varyans \% 20'ye yükselmiştir $(\mathrm{R}=.44, \mathrm{R} 2=.20 ; \mathrm{P}<.00)$. Sonuç olarak, iki aşamalı model toplam varyansın \% 20'sini yordamaktadır.

\section{Tartışma / Sonuç ve Öneriler}

Bu çalışma kapsamında öğretmen adaylarının çokkültürlü eğitime yönelik olumlu tutumlarının Suriyelilere yönelik toplumsal uzaklık düzeyleri azaldıkça arttığı ve bilişsel esneklik düzeyleri arttıkça arttığı sonucuna ulaşılmıştır. Yine yapılan analizler sonucunda öğretmen adaylarının çokkültürlü eğitime ilişkin tutumlarını yordamada toplumsal uzaklık ve bilişsel esneklik değişkenlerinin anlamlı bir rolü olduğu gözlenmiştir. Söz konusu değişkenler birlikte çokkültürlü eğitime yönelik tutumun \%20'sini yordamaktadır. Modele en fazla katkısı olan değişken toplumsal uzaklık değiş̧kenidir. Toplumsal uzaklıktan daha az olsa da bilişsel esneklik de öğretmen adaylarının çokkültürlü eğitime yönelik tutumlarını yordamaktadır. Yani öğretmen adaylarının çokkültürlü eğitime yönelik tutumlarında hem kişisel özelliklerinin hem de toplumsal olarak diğer gruplara bakışlarının etkili olduğu görülmektedir.

Çokkültürlü eğitime yönelik tutumun toplumsal uzaklık değişkeni ile ilişkili olması ve bu değişken tarafından yordanması bu araştırmada ortaya çıkan önemli bir bulgudur. Alanyazın incelendiğinde Brandwein ve Donoghue (2011) tarafından yapılan bir çalışmada da ortaokul öğrencilerine uygulanan bir çokkültürlü eğitim programının öğrencilerin toplumsal uzaklık düzeyini azalttığı sonucuna ulaşıldığı gözlenmiştir. Bu bulgu araştırmamızın sonuçlarıyla da paraleldir. Bu konuda karşılıklı bir ilişkinin olduğunu söylemek mümkündür. Çokkültürlü eğitime yönelik olumlu tutumun yüksek olması toplumsal uzaklığın az olmasını da beraberinde getirmektedir. Bu durumun önyargılar ile ilgili olduğu düşünülmektedir. Farklı gruplara yönelik önyargısı yüksek olan kişilerin toplumsal uzaklığının daha yüksek olduğu ve bunun çokkültürlü eğitime yönelik tutumunda da rol oynadığını söylemek mümkündür.

Literatürde öğretmenlerin çokkültürlü eğitime yönelik tutumunun incelendiği araştırmalara rastlanmaktadır. Örneğin Akman ve İmamoğlu-Akman (2017) tarafından yapılan bir araştırmada öğretmenlerin çokkültürlü eğitime yönelik tutumları ve sosyal zekâları arasında pozitif yönde anlamlı bir ilişki olduğu saptanmıştır. Bulut ve Sarıçam (2016) ise okulöncesi öğretmenleri ve öğretmen adaylarının çokkültürlü eğitime yönelik tutumlarının kültürel empati, esneklik, sosyal girişkenlik, açık görüşlülük ve duygusal denge boyutlarını içeren çokkültürlü kişilik değişkeni tarafından yordandığını saptamışlardır. Bu bulgular araştırmamızda da ortaya çıkan öğretmen adaylarında bilişsel esnekliğin çokkültürlü eğitime yönelik tutumu yordaması sonucu ile paraleldir. Farklı inanç, görüş ve grupları uzlaştırabilen ve çalışan ve çokkültürlü ortamlarda hizmet verebilen kişiler olmaları beklenen öğretmenlerin (Şişman, 2006) bilişsel esneklik özelliğine sahip olmasının özellikle önemli olduğu düşünülmektedir. Bilişsel esneklik özelliği olan öğretmenlerin daha kapsayıcı eğitim ortamlarının düzenlenmesinde kilit önemde olduğu açıktır.

Eğitim gibi bir alanda hizmet verirken bireyin içinde yetiştiği kültürün göz ardı edilmesi birey hakkındaki çok önemli verileri elde edememe veya yanlış verilerle hareket etme sonucunu da beraberinde getirecektir. Bu riskin önüne geçmek ancak çokkültürlülük konusunda farkındalık kazanılması ve çokkültürlü eğitimin avantajlarının görülebilmesiyle mümkün olacaktır. Çokkültürlü eğitime yönelik olumlu tutuma sahip olmak ise günümüzde öğretmenlerin sahip olması gereken bir nitelik olarak ön plana çıkmaktadır.

Çokkültürlü eğitime yönelik olumlu tutum geliştirilmesi için farklılıkların aynı potada eritilecek özellikler olarak değil zenginlik olarak değerlendirilmesi gerekmektedir. Bunun için de diğer gruplara yönelik toplumsal mesafenin azaltılması önem taşımaktadır. Bunun için ise öğretmen eğitiminin çokkültürlülüğe ilişin farkındalıkları arttırıcı bir içeriğe sahip olması 
gerekmektedir. Öğretmen ve öğretmen adaylarının kendi kültürel kimliklerinin ve hizmet verecekleri grupların kültürel özelliklerinin farkında olması eğitim ortamlarının daha verimli olmasını da beraberinde getirecektir (Chisholm, 1994). Türkiye'nin hem kendi kültürel çeşitliliği hem de göç vb. olgularla daha da yaygınlaşan çokkültürlü yapısı bunu daha da elzem kılmaktadır.

$\mathrm{Bu}$ temelde öğretmenlerde çokkültürlü eğitim konusunda farkındalık ve olumlu tutum geliştirmeye yönelik çalışmaların yapılmasının önemli olduğu düşünülmektedir. Özelikle Milli Eğitim Bakanlığı'nın bu konuda çeşitli çalışmalar yapmaya başlamasını bu ihtiyacın pratikte hissedilmesinin bir işareti olarak okumak mümkündür. Örneğin Milli eğitim bakanlığ tarafından UNICEF ile işbirliği içinde yürütülen " yabancı uyruklu öğrencilerin eğitimine ilişkin öğretmenlerin pedagojik bilgi ve becerilerinin artırılmasını ve ögrencilerin Türk eğitim sistemine uyumlarını kolaylaştırmayı amaçlayan "sınıfında yabancı uyruklu öğrenci bulunan öğretmenlerin eğitimi" programını (Aktekin, 2017) bu kapsamda değerlendirmek mümkündür. $\mathrm{Bu}$ eğitimlerin sadece sınıfında yabancı uyruklu öğrenci bulunan öğretmenler için değil genel anlamda yaygınlaşması ve çokkültürlü eğitime yönelik farkındalığın öğretmenlerin eğitim sürecine de entegre edilmesinin çağın ihtiyaçlarına daha uygun eğitimcilerin yetiştirilmesine katkıda bulunacă̆ düşünülmektedir.

$\mathrm{Bu}$ araştırmada öğretmen adaylarının çokültürlü eğitime yönelik tutumları ve bunları yordadığı düşünülen toplumsal uzaklıkları ve bilişsel esneklik özellikleri incelenmiştir. Çokkültürlülük sadece öğretmenlerin değil, toplumun her kesiminin etkilendiği bir faktördür. Bireylerin çokkültürlülüğe yönelik tutumlarının kendi kültüründen farklı olan kişilere yönelik davranışlarını da etkileyeceği öngörülmektedir. $\mathrm{Bu}$ nedenle bundan sonraki araştırmalarda sağlık çalışanları, ruh sağlığı alanında çalışan kişiler, sosyal hizmet uzmanları, vb. hizmet alanlarında çalışan kişilerin çokkültürlülüğe yönelik tutumlarını belirlemeye yönelik araştırmalar yapmanın faydalı olacağı düşünülmektedir.

\section{Kaynaklar}

Akman, Y. ve İmamoğlu-Akman, G. (2017). The investigation of teachers' multicultural education attitude according to the perception of social intelligence. Sakarya University Journal of Education, 7(1), 34-48.

Aktaş, E. ve Gülçür, İ. (2017). Suriyelilere yönelik toplumsal kabulü ve uyumu etkileyen sosyoekonomik faktörler: Mersin ili Mezitli ilçesi örneği. Toplum ve Demokrasi Dergisi, 11(23), 235-248.

Aktekin, S. (2017). Sınıfinda yabancı uyruklu öğrenci bulunan ögretmenler için el kitabı. Ankara: MEB Yayınları.

APA (2002). Guidelines on multicultural education, training, research, practice, and organizational change for psychologists- American Psychological Association. Erişim adresi: http://apa.org/pi/oema/resources/policy/multicultural-guidelines.aspx ?item=5]

Banks, J. A. (2008). Diversity, group identity, and citizenship education in a global age. Educational researcher, 37(3), 129-139.

Baysal, A. C. (1981). Sosyal psikolojide tutumlara teorik bir yaklaşım. İ.Ü. İsletme Fakültesi Dergisi, Mart, 121-138.

Bichi, R. (2008). Mixed approach to measuring social distance. Cognition, Brain, Behavior. An Interdisciplinary Journal, 12(4), 487-508.

Bilgin, M. (2009). Bilişsel esnekliği yordayan bazı değişkenler. Çukurova Üniversitesi Eğitim Fakültesi Dergisi, 3(36), 142-157.

Bogardus, Emory S. (1925). Measuring social distances. Journal of Applied Sociology, 9, 299308.

Bogardus, Emory S. (1926). Social distance in the city. Proceedings and Publications of the American Sociological Society, 20, 40-46.

Brandwein, D. ve Donoghue, C. (2011). A multicultural grassroots effort to reduce ethnic and racial social distance among middle school students. Multicultural Education, 19(1), 3843. 
Bulut, M. ve Sarıçam, H. (2016). Okul öncesi öğretmen ve öğretmen adaylarinda çokkültürlü kişiliğin çokkültürlü eğitim tutumlari üzerindeki etkisinin incelenmesi. Kırıkkale Üniversitesi Sosyal Bilimler Dergisi, 6(1), 295-322.

Cañas, J. J., Fajardo, I. ve Salmerón, L. (2013). Cognitive flexibility. Erişim adresi: http://www.ugr.es/ ergoco gn/articulos/cognitive-flexibilityl.pdf

Cengiz, D. (2015). Zorunlu göçün mekânsal etkileri ve yerel halkın algısı; Kilis örneği. Electronic Turkish Studies, 10(2), 101-122.

Chisholm, I. M. (1994). Preparing teachers for multicultural classrooms. The Journal of Educational Issues of Language Minority Students, 14(11), 43-68.

Chung, S., Fangsu, Y. ve Wensu, S. (2012). The impact of cognitive flexibility on resistance to organizational change. Social Behavior and Personality. 40(5), 735-746

Cırık, İ. (2008). Çok kültürlü eğitim ve yansımaları. Hacettepe Üniversitesi Eğitim Fakültesi Dergisi, 34, 27-40.

Coenders, M., Lubbers, M. ve Scheepers, P. (2005). Majority populations' attitudes towards migrants and minorities. Report for the European Monitoring Centre on Racism and Xenophobia. Wien: EUMC.

Coenders, M., Lubbers, M. ve Scheepers, P. (2003). Majority populations attitudes towards migrants and minorities. Report for the European Monitoring Centre on Racism and Xenophobia, Ref. no. 2003/04/01. Erişim adresi: http://fra.europa.eu/fra Website /attachments/ Report-1.pdf

Charness, G. ve Gneezy, U. (2008). What's in a name? Anonymity and social distance in dictator and ultimatum games. Journal of Economic Behavior \& Organization, 68(1), 29-35.

Çelikkaleli, Ö. (2014). Bilişsel Esneklik Ölçeği'nin geçerlik ve güvenirliği. Eğitim ve Bilim, 39(176), 339-346.

Çiftçi, H. (2018). Türkiye Cumhuriyeti vatandaşlarının suriyeli sığınmacılara yönelik tutum, alg1 ve empatik eğilimlerinin analizi. Itobiad: Journal of the Human \& Social Science Researches, 7(3), 2232-2256.

Çömez Polat, F. ve Kaya, E. (2017). Bir ötekileştirme pratiği: Türkiye'de yaşayan Suriyelilere yönelik tutumlar. Mersin Üniversitesi Sosyal Bilimler Enstitüsü Dergisi, 1(1), 38-48.

Diril, A. (2011). Lise öğrencilerinin bilişsel esneklik düzeylerinin sosyo-demografik değişkenler ve öfke düzeyi ile öfke ifade tarzları arasindaki ilişki açısından incelenmesi (Yayımlanmamış yüksek lisans tezi). Çukurova Üniversitesi Sosyal Bilimler Enstitüsü, Adana.

Erdoğan, M. M. (2014). Türkiye'deki Suriyeliler: Toplumsal kabul ve uyum araştırması. Hacettepe Üniversitesi Göç ve Siyaset Araştırmaları Merkezi, Ankara.

Erkuş, A. (2011). Davranış bilimleri için bilimsel araştırma süreci, Seçkin Yay., Ankara

Kabaklı Çimen, L. ve Ersoy Quadır, S. (2018). Üniversite öğrencilerinin Suriyeli sığınmacılarla ilgili tutumlarının sivil katılımları bağlamında incelenmesi. Itobiad: Journal of the Human \& Social Science Researches, 7(2), 1251-1273.

Gay, G. (1994). A synthesis of scholarship in multicultural education. urban monograph series. 26. Erişim adresi: http://files.eric.ed.gov/fulltext/ED378287.pdf

Gay, G. (2002). Preparing for culturally responsive teaching. Journal of Teacher EducationWashington Dc, 53(2), 106-116.

Gülüm, İ. V. ve Dağ, İ (2012) .Tekrarlayıcı düşünme ölçeği ve bilişsel esneklik envanterinin Türkçe'ye uyarlanması, geçerliliği ve güvenilirliği. Anatolian Journal of Psychiatry, 13, 216-223.

Gündüz, B. (2013). Emotional intelligence, cognitive flexibility and psychological symptoms in pre-service teachers. Educational research and reviews, 8(13), 1048-1056.

Kaptanbaş Gürbüz, E. ve Sezgin Nartgün, Ş. (2018). Pedagojik formasyon programı öğrencilerinin bilişsel esneklik ve öz yeterlik düzeyleri. Journal of International Social Research, 11(55), 628-640. 
Kearsley, G. (2000). Cognitive flexibility theory. Erişim adresi: http://www.gwu.edu/ tip/spiro.html

Koc, Y. ve Anderson, J. R. (2018). Social distance toward Syrian refugees: The role of intergroup anxiety in facilitating positive relations. Journal of Social Issues, 74(4), 790811.

Man, F. (2016). "Günah keçileri” ya da "Olağan şüpheliler" olarak Suriyeliler. Çalışma ve Toplum, 3, 1147-1170.

Martin, M. M. ve Anderson, C. M. (1998). Cognitive flexibility scale: Three validity studies. Communication Reports, 11(1), 1-9.

Nieto, S. ve Bode, P. (2008). Affirming diversity, The Sociopolitical context of multicultural education (5th ed.). Boston: Allyn \& Bacon. 2007).

Ponterotto, J. G., Baluch, S., Greig T. ve Rivera, L. (1998). Development and initial score validation of the teacher multicultural attitude survey. Educational and Psychological Measurement, 58(6), 1002-1016.

Sağlam, H. İ. ve Kanbur, N. İ. (2017). Sınıf öğretmenlerinin mülteci öğrencilere yönelik tutumlarının çeşitli değişkenler açısından incelenmesi. Sakarya University Journal of Education, 7(2), 310-323.

Seçer, İ. (2015). Psikolojik test geliştirme süreci. Ankara: Anı Yayınc1lık.

Şişman, M. (2006). Ĕğitim bilimine giriş. 2.Baskı, PegemA Yayıncılık, Ankara,.

Tavşancıl, E. (2006). Tutumların ölçülmesi ve SPSS ile veri analizi. Ankara: Nobel Yayın Dağıtım.

Topkaya, Y. ve Akdağ, H. (2016). Sosyal bilgiler öğretmen adaylarının Suriyeli sığınmacılar hakkındaki görüşleri (Kilis 7 Aralık Üniversitesi örneği). Çankırı Karatekin Üniversitesi Sosyal Bilimler Enstitüsü Dergisi, 7(1), 767-786.

Üzümcü, B. ve Müezzin, E. E. (2018). Öğretmenlerin bilişsel esneklik ve mesleki doyum düzeyinin incelenmesi. Sakarya University Journal of Education, 8(1), 8-25.

Yaşar Ekici, F. ve Balcı, S. (2019). Okul öncesi öğretmen adaylarının bilişsel esneklik düzeyleri ve duygusal tepkisellik düzeylerinin incelenmesi. Yüksekögretim ve Bilim Dergisi, 9(1), 65-77.

Yazıc1, S., Başol, G. ve Toprak, G. (2009). Öğretmenlerin çokkültürlü eğitim tutumları: Bir güvenirlik ve geçerlik çalışması. Hacettepe Üniversitesi Eğitim Fakültesi Dergisi, 37(37), 229-242.

Yıldırımalp, S. ve İyem, C. (2017). Suriyeli siğinmacilarin toplumsal kabul ve uyum sürecine ilişkin bir araştirma. Bilgi Sosyal Bilimler Dergisi, (2), 107-126.

Birleşmiş Milletler Mülteciler Yüksek Komiserliği (UNHCR) (2018). Türkiye'deki mülteciler ve siğınmacılar. 15. 05. 2018, Erişim adresi: http://www.unhcr.org/tr/turkiyedekimulteciler-ve-siginmacilar

\section{Extended Abstract}

\section{Introduction}

Multiculturalism is a multi-faceted concept that includes race, ethnicity, language, sexual orientation, gender, age, disability, social class, religious orientation and other cultural dimensions (APA, 2002). One of the areas where multiculturalism is most discussed is education. Banks (2008) defines multicultural education as an educational approach that provides ethnic, cultural and linguistic alternatives to all students and ensures that all students enjoy the right to equal education. In modern societies, individuals raised are expected to interact with different cultures and develop positive attitudes in their interactions (Cirik, 2008). Therefore, multicultural education is one of the important requirements of our age.

In this study, one of the variables thought to be the determinant of teachers' attitudes towards multicultural education is social distance. In general, the social distance is defined as absence of openness at a varying extent towards the individuals outside of the social category that one belongs to (Bichi, 2008). Bogardus found strong evidence to support this claim, created 
a permanent research tradition with these evidence, and pioneered contemporary research that still yields similar results on social distance (Coenders, Lubbers \& Scheepers, 2005).

Negative attitudes towards groups from a different country are widespread worldwide and are typically hostile because most immigrant countries perceive immigrants as a security threat and an economic burden (Koç \& Anderson, 2018). Although for Syrians who immigrated to Turkey that negative attitudes were less is was stated in some research findings particulary, the increase in the number of Syrians living in Turkey and the understanding that they will not return their country has brought to evolve towards negative positive perception (Cengiz, 2015; Erdoğan, 2014, Yıldırımalp, İslamoğlu \& İyem, 2017). Studies show that the Turkish society has established a very serious cultural distance with Syrians and that it does not look at giving citizenship at all (Aktaş \& Gülçur, 2017; Erdoğan, 2014).

It is thought that the personal characteristics of teachers may also be effective in their attitudes. One of these is cognitive flexibility. Cognitive flexibility is the ability to change cognitions according to changing environmental conditions (Gülüm \& Dağ, 2012).

In this context, this study aims to examine whether teacher candidates' attitudes towards multicultural education are predicted by the variables of social distance and cognitive flexibility towards Syrian refugees.

\section{Method}

526 pre-service teachers, $285(54.2 \%)$ females and $241(45.8 \%)$ males who attended the Pedagogical Formation training at Mersin University Faculty of Education in the 2017-2018 academic year participated in the study. In obtaining research data Cognitive Flexibility Scale, developed by Martin and Rubin (1995 cited in Çelikkaleli, 2014) and adapted to Turkish by Çelikkaleli (2014), Multicultural Attitude Scale of Teachers developed by Ponterotto, Baluch, Greid and Rivere (1998) and adapted to Turkish by Yazıc1, Başol and Toprak (2009), Bogardus Social Distance Scale developed by Bogardus in 1925 and Personal Information Form were used. Gradual multiple linear regression analysis was used in the analysis of the data.

\section{Findings}

The results showed that there was a positive significant relationship between positive attitudes towards multicultural education and low social distance $(r=356)$. Also, a positive significant relationship between positive attitudes towards multicultural education and cognitive flexibility $(\mathrm{r}=.258)$ was observed. Stepwise Linear Regression Analysis was performed to determine whether pre-service teachers' attitudes towards multicultural education is predicted by social distance and cognitive flexibility. The result of regression analysis showed that variables of social distance and cognitive flexibility had a significant role on predicting pre-service teachers' attitudes towards multicultural education $(\mathrm{F}=75,84, \mathrm{p}<0,05)$. As a result, the two-step model explains $20 \%$ of the total variance.

\section{Conclusion and Discussion}

As a result of this study, it was concluded that the positive attitudes of teacher candidates towards multicultural education increase as the social distance levels towards Syrians decrease and their cognitive flexibility levels increase. In addition, as a result of the analyzes, it was observed that social distance and cognitive flexibility variables had a significant role in predicting the attitudes of prospective teachers towards multicultural education. These variables together predict $20 \%$ of the attitude towards multicultural education. The variable that contributes most to the model is the social distance variable. Cognitive flexibility, though less than social distance, predicts pre-service teachers' attitudes towards multicultural education. In other words, it is seen that both personal characteristics and social view of other pre-service teachers are effective in their attitudes towards multicultural education.

The fact that the attitude towards multicultural education is related to the variable of social distance and predicted by this variable is an important finding in this research. In a study conducted by Brandwein and Donoghue (2011) in the literature, it was observed that a 
multicultural education program applied to secondary school students decreased the level of social distance of students. This finding is in line with the results of our research. It is possible to say that there is a mutual relationship in this regard. The high positive attitude towards multicultural education brings along a low social distance. This situation is thought to be related to prejudices. It is possible to say that people with high prejudices towards different groups have a higher social distance and this also plays a role in their attitude towards multicultural education.

Awareness of the cultural identities of the teachers and pre-service teachers on their cultural identities and the cultural characteristics of the groups they will serve will bring educational environments more functional (Chisholm, 1994). Turkey is both its cultural diversity as well as immigration and so on. The multicultural structure, which is becoming more and more widespread, makes this even more essential. 